\title{
Glycated haemoglobin A1c for diagnosing diabetes in Chinese population: cross sectional epidemiological survey
}

\author{
Yuqian Bao, professor Xiaojing Ma, assistant professor Huating Li, PhD student Mi Zhou, PhD student Cheng \\ $\mathrm{Hu}$, assistant professor Haiya Wu, assistant professor Junling Tang, technician Xuhong Hou, assistant \\ professor Kunsan Xiang, professor Weiping Jia, professor
}

\begin{abstract}
Department of Endocrinology and Metabolism, Shanghai Jiao Tong University Affiliated Sixth People's Hospital, Shanghai Diabetes Institute, Shanghai Clinical Center of Diabetes, Shanghai 200233, China

Correspondence to: $\mathrm{W}$ Jia wpjia@sjtu.edu.cn
\end{abstract}

Cite this as: $B M J$ 2010;340:c2249 doi:10.1136/bmj.c2249

\section{ABSTRACT}

Objectives To evaluate haemoglobin $\mathrm{A} 1 \mathrm{c}\left(\mathrm{HbA}_{1 \mathrm{c}}\right)$ in diagnosing diabetes and identify the optimal $\mathrm{HbA}_{1 \mathrm{c}}$ threshold to be used in Chinese adults.

Design Multistage stratified cross sectional epidemiological survey.

Setting Shanghai, China, 2007-8.

Participants 4886 Chinese adults over 20 years of age with no history of diabetes.

Main outcome measures Performance of $\mathrm{HbA}_{1 \mathrm{c}}$ at increasing thresholds for diagnosing diabetes.

Results The area under the receiver operating characteristics curve for detecting undiagnosed diabetes was 0.856 (95\% confidence interval 0.828 to 0.883 ) for $\mathrm{HbA}_{1 \mathrm{c}}$ alone and 0.920 (0.900 to 0.941) for fasting plasma glucose alone. Very high specificity $(96.1 \%, 95 \%$ confidence interval $95.5 \%$ to $96.7 \%$ ) was achieved at an $\mathrm{HbA}_{1 \mathrm{c}}$ threshold of $6.3 \%$ (2 SD above the normal mean). Moreover, the corresponding sensitivity was $62.8 \%$ ( $57.1 \%$ to $68.3 \%$ ), which was equivalent to that of a fasting plasma glucose threshold of $7.0 \mathrm{mmol} / \mathrm{l}(57.5 \%$, $51.7 \%$ to $63.1 \%$ ) in detecting undiagnosed diabetes. In participants at high risk of diabetes, the $\mathrm{HbA}_{1 \mathrm{c}}$ threshold of $6.3 \%$ showed significantly higher sensitivity $(66.9 \%$, $61.0 \%$ to $72.5 \%$ ) than both fasting plasma glucose $\geq 7.0 \mathrm{mmol} / \mathrm{l}(54.4 \%, 48.3 \%$ to $60.4 \%)$ and $\mathrm{HbA}_{1 \mathrm{c}} \geq 6.5 \%$ (53.7\%, 47.6\% to 59.7\%) (P<0.01).

Conclusions $\mathrm{An} \mathrm{HbA}_{1 \mathrm{c}}$ threshold of $6.3 \%$ was highly specific for detecting undiagnosed diabetes in Chinese adults and had sensitivity similar to that of using a fasting plasma glucose threshold of $7.0 \mathrm{mmol} / \mathrm{l}$. This optimal $\mathrm{HbA}_{1 \mathrm{c}}$ threshold may be suitable as a diagnostic criterion for diabetes in Chinese adults when fasting plasma glucose and oral glucose tolerance tests are not available.

\section{INTRODUCTION}

Diabetes is often not diagnosed until complications appear, and approximately $30 \%$ of people with diabetes may be undiagnosed. ${ }^{12}$ Additionally, complications of diabetes have become a leading cause of impairment of human health. ${ }^{3}$ More efficient approaches to diagnosing diabetes urgently need be developed to improve health care for patients with diabetes.
Existing diagnostic methods include plasma glucose specific tests (fasting plasma glucose or oral glucose tolerance test) and glycated haemoglobin A1c $\left(\mathrm{HbA}_{1 \mathrm{c}}\right)$, although the last method has not been recommended as a diagnostic tool mainly owing to the lack of standardised results. ${ }^{45}$ The special requirements for the oral glucose tolerance test, or to obtain fasting and two hour postprandial plasma glucose, limit the clinical application of these methods. $\mathrm{HbA}_{1 \mathrm{c}}$ tests are convenient and easy to do without regard to the time elapsed since the previous meal.

Several methods have been used to measure $\mathrm{HbA}_{1 \mathrm{c}}$, including low performance liquid chromatography, ion exchange high performance liquid chromatography, capillary electrophoresis, and immunoassay. Under the leadership of the National Glycohemoglobin Standardization Program, great progress has been made in standardising $\mathrm{HbA}_{1 \mathrm{c}}$ assays in many nations worldwide, ${ }^{67}$ and high performance liquid chromatography is highly recommended. In China, hospitals in large and medium sized cities that participated in the Chinese Ministry of Health Quality Assessment Program for $\mathrm{HbA}_{1 \mathrm{c}}$ used this method. In recent years, $\mathrm{HbA}_{1 \mathrm{c}}$ has been widely used as a measure of glycaemic control in patients with diabetes after treatment, and efforts to further standardise its use have continued..$^{89}$

Substantial evidence shows that $\mathrm{HbA}_{1 \mathrm{c}}$ may be a useful tool for screening for and diagnosis of diabetes. ${ }^{10-14}$ An $\mathrm{HbA}_{1 \mathrm{c}}$ threshold of $6.5 \%$ was proposed for the diagnosis of diabetes on the basis of the data from the National Health and Nutrition Examination Survey. ${ }^{1011}$ However, findings from previous studies evaluating $\mathrm{HbA}_{1 \mathrm{c}}$ as a screening tool have suggested that the optimal threshold for detecting diabetes may vary by ethnic group. ${ }^{11215}$ Recently, an international expert committee with members appointed by the American Diabetes Association, the European Association for the Study of Diabetes, and the International Diabetes Federation published a report on the role of the $\mathrm{HbA}_{1 \mathrm{c}}$ assay in the diagnosis of diabetes. It noted that an $\mathrm{HbA}_{1 \mathrm{c}}$ value of $6.5 \%$ is sufficiently sensitive and specific to identify people who are at risk of developing retinopathy and who should therefore be diagnosed as having diabetes. 


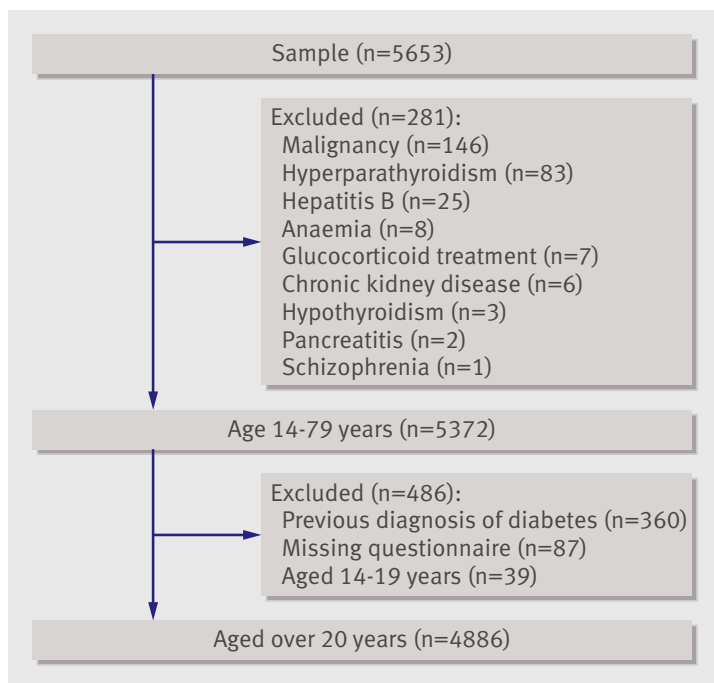

Fig 1| Flow diagram of recruitment of participants

The committee examined data from three cross sectional epidemiological studies that included an Egyptian population, Pima Indians, and the US National Health and Nutrition Examination Survey population. ${ }^{16}$ However, the performance of $\mathrm{HbA}_{1 \mathrm{c}}$ in detecting diabetes in the Chinese population remains unknown. The purpose of this study was to evaluate the efficiency of $\mathrm{HbA}_{1 \mathrm{c}}$ in diagnosing diabetes and to identify the optimal threshold in the adult Chinese population by using high performance liquid chromatography.

\section{METHODS}

\section{Study design and population}

This cross sectional epidemiological survey of diabetes and metabolic syndrome (Shanghai Diabetes Study II, SHDS II) in six communities in Shanghai between May 2007 and August 2008 followed a multistage stratified design. We divided each community into five groups according to age (20-29, 30-39, 40-49, 50-59, $\geq 60$ years). The sampling proportion within each group was based on the age structure of the community. The average response rate was $95.9 \%$. Exclusion criteria were cancer, severe psychiatric disturbance, chronic kidney disease, pregnancy, and glucocorticoid treatment. A total of 5372 Chinese people aged 14 to 79 years participated in the survey. All participants were expected to complete a uniform questionnaire containing questions about the histories of current and previous illness and medical treatment. Standard $75 \mathrm{~g}$ oral glucose tolerance tests were done in participants without known diabetes. We excluded 486 people, comprising 360 previously diagnosed as having diabetes, 87 with missing questionnaire data, and 39 aged under 20 years. We analysed data from 4886 participants aged over 20. Each participant gave written informed consent

\section{Anthropometric and biochemical measurements}

Participants arrived at the community service centre at 6 am after a 10 hour overnight fast. Each participant had a physical examination including measurement of height, weight, waist circumference, and blood pressure. We calculated body mass index as weight $(\mathrm{kg})$ divided by squared height $(\mathrm{m})$. We measured waist circumference at the horizontal plane between the inferior costal margin and the iliac crest on the mid-axillary line. Blood pressure was the average of three measurements made with a sphygmomanometer at two minute intervals.

After a fasting venous blood sample was drawn from the antecubital vein, each participant had a $75 \mathrm{~g}$ oral glucose tolerance test. We measured plasma glucose concentrations by the glucose oxidase method. We measured serum lipid profiles, including triglycerides, total cholesterol, high density lipoprotein cholesterol, and low density lipoprotein cholesterol, by standard commercial methods on a parallel, multichannel analyser (Hitachi 7600-020, Tokyo, Japan). An experienced technician, who was blinded to the study, measured $\mathrm{HbA}_{1 \mathrm{c}}$ by high performance liquid chromatography (HLC-73G7, Tosoh, Japan). We measured $\mathrm{HbA}_{1 \mathrm{c}}$, fasting plasma glucose, and two hour postload plasma glucose within two hours of collection of blood. The Shanghai Diabetes Institute successfully participated in the $\mathrm{HbA}_{1 \mathrm{c}}$ Quality Assessment Program of the Chinese Ministry of Health between 2006 and 2008. The $\mathrm{HbA}_{1 \mathrm{c}}$ inter-assay and intraassay coefficients of variation were $<0.4 \%$, and $<0.6 \%$.

\section{Definitions}

The oral glucose tolerance test is considered to be the gold standard for diagnosing diabetes. ${ }^{178}$ The glycaemic thresholds for diagnosis of diabetes and impaired glucose regulation were based on the 1999 World Health Organization (WHO) criteria. Diabetes is defined as fasting plasma glucose of at least $7.0 \mathrm{mmol} / \mathrm{l}$, two hour post-load plasma glucose of at least $11.1 \mathrm{mmol} / 1$, or both. ${ }^{4}$ Impaired glucose regulation is defined as impaired fasting glucose (fasting plasma glucose $\geq 6.1 \mathrm{mmol} / 1$ and $<7.0 \mathrm{mmol} / \mathrm{l}$ and two hour post-load plasma glucose $<7.8 \mathrm{mmol} / \mathrm{l}$ ), impaired glucose tolerance (fasting plasma glucose $<6.1 \mathrm{mmol} / \mathrm{l}$ and two hour post-load plasma glucose $\geq 7.8 \mathrm{mmol} / \mathrm{l}$ and $<11.1 \mathrm{mmol} / \mathrm{l}$ ), and impaired fasting glucose with impaired glucose tolerance (fasting plasma glucose $\geq 6.1 \mathrm{mmol} / 1$ and $<7.0 \mathrm{mmol} / 1$ and two hour post-load plasma glucose $\geq 7.8 \mathrm{mmol} / \mathrm{l}$ and $<11.1 \mathrm{mmol} / \mathrm{l})$. Hyperglycaemic categories of diabetes are isolated high fasting plasma glucose concentrations (fasting plasma glucose $\geq 7.0 \mathrm{mmol} / \mathrm{l}$ and two hour post-load plasma glucose $<11.1 \mathrm{mmol} / \mathrm{l})$, isolated high two hour post-load plasma glucose concentrations (fasting plasma glucose $<7.0 \mathrm{mmol} / \mathrm{l}$ and two hour post-load plasma glucose $\geq 11.1 \mathrm{mmol} / \mathrm{l}$ ), and high fasting plasma glucose concentrations with high two hour post-load plasma glucose concentrations (fasting plasma glucose $\geq 7.0 \mathrm{mmol} / 1$ and two hour post-load plasma glucose $\geq 11.1 \mathrm{mmol} / \mathrm{l}$ ).

\section{Statistical analysis}

We used SPSS version 11.5 for all statistical analyses. We presented continuous variables as means $(\mathrm{SD})$, 
Table 1 |Clinical characteristics of participants. Values are median (interquartile range) unless stated otherwise

\begin{tabular}{|c|c|c|c|}
\hline Characteristics & Total $(n=4886)$ & Men $(n=1828)$ & Women $(n=3058)$ \\
\hline Age (years) & $49.4(37.9-57.7)$ & $49.0(37.4-59.0)$ & $49.5(38.2-56.9)$ \\
\hline Body mass index $\left(\mathrm{kg} / \mathrm{m}^{2}\right)$ & $23.5(21.4-25.9)$ & Mean 24.1 (SD 3.3) & $23.2(21.2-25.5)^{\star}$ \\
\hline Waist circumference $(\mathrm{cm})$ & $79.0(72.0-86.0)$ & $84.0(77.0-90.0)$ & $76.0(70.0-83.0)^{\star}$ \\
\hline Systolic blood pressure $(\mathrm{mm} \mathrm{Hg})$ & $120.0(110.0-130.0)$ & $120.0(112.1-134.0)$ & $120.0(109.0-130.0)^{\star}$ \\
\hline Diastolic blood pressure $(\mathrm{mm} \mathrm{Hg})$ & $78.0(70.0-82.0)$ & $80.0(71.7-88.0)$ & $76.0(70.0-80.0)^{\star}$ \\
\hline Total cholesterol (mmol/l) & $4.5(4.0-5.2)$ & $4.5(3.9-5.1)$ & $4.6(4.0-5.3)^{\star}$ \\
\hline Triglycerides (mmol/l) & $1.3(0.9-1.9)$ & $1.5(1.0-2.2)$ & $1.2(0.8-1.7)^{\star}$ \\
\hline High density lipoprotein cholesterol $(\mathrm{mmol} / \mathrm{l})$ & $1.3(1.1-1.5)$ & $1.2(1.0-1.4)$ & $1.4(1.2-1.6)^{\star}$ \\
\hline Low density lipoprotein cholesterol $(\mathrm{mmol} / \mathrm{l})$ & $2.9(2.4-3.4)$ & $2.9(2.4-3.4)$ & $2.9(2.4-3.4)$ \\
\hline Fasting plasma glucose (mmol/l) & $5.2(4.8-5.6)$ & $5.2(4.7-5.6)$ & $5.2(4.8-5.6)$ \\
\hline 2 hour post-load plasma glucose $(\mathrm{mmol} / \mathrm{l})$ & $6.0(5.0-7.2)$ & $5.9(4.8-7.3)$ & $6.0(5.1-7.2)$ \\
\hline$\underline{\mathrm{HbA}_{1 \mathrm{c}}(\%)}$ & $5.6(5.3-5.9)$ & $5.6(5.4-5.9)$ & $5.6(5.3-5.8)^{\star}$ \\
\hline Normal glucose tolerance-No (\%) & $3748(76.7)$ & $1362(74.5)$ & $2386(78.0)^{\star}$ \\
\hline Impaired glucose regulation—No (\%) & $837(17.1)$ & $315(17.2)$ & $522(17.1)$ \\
\hline Undiagnosed diabetes—No (\%) & $301(6.2)$ & $151(8.3)$ & $150(4.9)^{*}$ \\
\hline Fasting plasma glucose $\geq 7.0 \mathrm{mmol} / \mathrm{l}-\mathrm{No}(\%)$ & $173(58)$ & $87(58)$ & $86(58)$ \\
\hline $\begin{array}{l}2 \text { hour post-load plasma glucose } \geq 11.1 \mathrm{mmol} / \mathrm{l} \text { and } \\
\text { fasting plasma glucose }<7.0 \mathrm{mmol} / \mathrm{l}-\mathrm{No}(\%)\end{array}$ & $128(43)$ & $64(42)$ & $64(43)$ \\
\hline
\end{tabular}

except for skewed variables, which we presented as medians (interquartile range). We expressed categorical variables as percentages. We used Pearson correlation analysis to investigate the association of $\mathrm{HbA}_{1 \mathrm{c}}$ with blood glucose concentrations (that is, fasting plasma glucose and two hour post-load plasma glucose). We used the method described by Hanley and $\mathrm{McNeil}$ to compare the area under the receiver operating characteristics curve for $\mathrm{HbA}_{1 \mathrm{c}}$ and fasting plasma glucose predicting undiagnosed diabetes. ${ }^{19} \mathrm{We}$ examined the sensitivity and specificity of $\mathrm{HbA}_{1 \mathrm{c}}$ with the receiver operating characteristics curve to identify participants as having undiagnosed diabetes. Thresholds were $1,2,3$, and 4 standard deviations above the normal mean. We considered P values less than 0.05 to be statistically significant for a two sided test.

\section{RESULTS}

The final dataset included 4886 participants (1828 men and 3058 women) aged over 20 (median 49.4, interquartile range 37.9-57.7 years) from May 2007 to August 2008 (fig 1). Table 1 shows the clinical characteristics of the participants. We found no significant differences in age, low density lipoprotein cholesterol, fasting plasma glucose, and two hour post-load plasma glucose between men and women. Women had lower values of body mass index, waist circumference, blood pressure, triglycerides, and $\mathrm{HbA}_{1 \mathrm{c}}$ and higher levels of total cholesterol and high density lipoprotein cholesterol than did men (all $\mathrm{P}<0.01$ ). The percentage of undiagnosed diabetes in women was significantly lower than that in men $(\mathrm{P}<0.01)$.

The dataset included data from 3748 people with normal glucose tolerance, 837 with impaired glucose regulation, and 301 with diabetes. Of the 837 participants with impaired glucose regulation, 199 (23.8\%) had impaired fasting glucose, $534(63.8 \%)$ had impaired glucose tolerance, and $104(12.4 \%)$ had impaired fasting glucose with impaired glucose tolerance. Of the 301 participants with diabetes, 71 (24\%) had isolated high fasting plasma glucose concentrations, $128(43 \%)$ had isolated high two hour post-load plasma glucose concentrations, and 102 (34\%) had high fasting plasma glucose concentrations with high two hour post-load plasma glucose concentrations. $\mathrm{HbA}_{1 \mathrm{c}}$ and either fasting plasma glucose or two hour post-load plasma glucose were significantly correlated, with correlation coefficients of $0.619(\mathrm{P}<0.001)$ and $0.622(\mathrm{P}<0.001)$ on the basis of Pearson correlation analysis.

The receiver operating characteristics curve shown in figure 2 represents the diagnostic accuracy of $\mathrm{HbA}_{1 \mathrm{c}}$ for undiagnosed diabetes. The area under the curve was 0.856 (95\% confidence interval 0.828 to 0.883 ) for $\mathrm{HbA}_{1 \mathrm{c}}$ alone and 0.920 (0.900 to 0.941 ) for fasting plasma glucose alone. The two areas differed significantly from each other $(\mathrm{P}<0.001)$. Table 2 shows the sensitivity, specificity, positive predictive value, negative predictive value, positive likelihood ratio, and negative likelihood ratio for identifying diabetes at $\mathrm{HbA}_{1 \mathrm{c}}$ thresholds of 1, 2, 3, and 4 standard deviations $(0.4 \%)$ above the mean of normal glucose tolerance $(5.5 \%)$. When the number of standard deviations increased, sensitivity decreased and specificity increased. An $\mathrm{HbA}_{1 \mathrm{c}}$ threshold of $1 \mathrm{SD}$ above the normal mean $(5.9 \%)$ showed a very high sensitivity of $77.7 \%$ (95\% confidence interval $72.6 \%$ to $82.3 \%$ ) and a moderate specificity of $78.2 \%(77.0 \%$ to $79.4 \%)$ for detecting undiagnosed diabetes. These findings coincided with the threshold selected by the closest distance to the left upper corner of the receiver operating characteristics curve, which indicated the best trade-off between sensitivity and specificity. A high specificity of $96.1 \% \quad(95.5 \%$ to $96.7 \%)$ was 
Table 2 | Sensitivity, specificity, positive predictive value, negative predictive value, positive likelihood ratio, and negative likelihood ratio for detecting diabetes with fasting plasma glucose (FPG) in 1999 WHO criteria and $\mathrm{HbA}_{1 \mathrm{c}}$ thresholds $(\mathrm{n}=4886)$. Values in parentheses are $95 \%$ confidence intervals

\begin{tabular}{|c|c|c|c|c|c|c|}
\hline & $\begin{array}{l}\text { Sensitivity } \\
(\%)\end{array}$ & $\begin{array}{l}\text { Specificity } \\
(\%)\end{array}$ & $\begin{array}{l}\text { Positive predictive } \\
\text { value (\%) }\end{array}$ & $\begin{array}{c}\text { Negative predictive } \\
\text { value (\%) }\end{array}$ & $\begin{array}{l}\text { Positive likelihood } \\
\text { ratio }\end{array}$ & $\begin{array}{l}\text { Negative likelihood } \\
\text { ratio }\end{array}$ \\
\hline \multicolumn{7}{|l|}{$\mathrm{HbA}_{1 \mathrm{c}}$ threshold (\%): } \\
\hline 5.9 (1 SD above normal mean) & 77.7 (72.6 to 82.3$)$ & $78.2(77.0$ to 79.4$)$ & $19.0(16.8$ to 21.3$)$ & $98.2(97.7$ to 98.6$)$ & 3.6 (3.3 to 3.9$)$ & $0.3(0.2$ to 0.4$)$ \\
\hline 6.3 (2 SD above normal mean) & 62.8 (57.1 to 68.3 ) & 96.1 (95.5 to 96.7$)$ & 51.5 (46.3 to 56.7$)$ & 97.5 (97.0 to 98.0$)$ & $16.2(13.7$ to 19.1$)$ & $0.4(0.3$ to 0.5$)$ \\
\hline 6.7 (3 SD above normal mean) & 37.9 (32.4 to 43.6$)$ & 99.1 (98.7 to 99.3$)$ & $72.6(64.9$ to 79.4$)$ & 96.1 (95.5 to 96.6$)$ & 40.4 (29.0 to 56.2$)$ & $0.6(0.6$ to 0.7$)$ \\
\hline 7.1 (4 SD above normal mean) & 26.3 (21.4 to 31.6 ) & 99.8 (99.6 to 99.9$)$ & 87.8 (79.2 to 93.7$)$ & 95.4 (94.8 to 96.0$)$ & 109.7 (59.0 to 203.8) & 0.7 (0.7 to 0.8$)$ \\
\hline $6.5^{*}$ & 50.5 (44.7 to 56.3$)$ & 98.1 (97.6 to 98.4$)$ & 63.1 (56.6 to 69.2$)$ & $96.8(96.2$ to 97.3$)$ & 26.0 (20.6 to 32.9$)$ & $0.5(0.5$ to 0.6$)$ \\
\hline $\mathrm{FPG} \geq 7.0 \mathrm{mmol} / \mathrm{l}$ & $57.5(51.7$ to 63.1$)$ & $100.0(99.9$ to 100.0$)$ & 100.0 (97.9 to 100.0$)$ & 97.3 (96.8 to 97.7$)$ & - & $0.4(0.4$ to 0.5$)$ \\
\hline
\end{tabular}

*Threshold recommended by American Diabetes Association/European Association for the Study of Diabetes/International Diabetes Federation.

achieved at an $\mathrm{HbA}_{1 \mathrm{c}}$ threshold of $6.3 \%$ (2 $\mathrm{SD}$ above the normal mean), together with a low negative likelihood ratio of 0.4 (0.3 to 0.5$)$, a high positive likelihood ratio of 16.2 (13.7 to 19.1 ), and a negative predictive value of $97.5 \%(97.0 \%$ to $98.0 \%)$.

Subsequently, we compared the sensitivity of $\mathrm{HbA}_{1 \mathrm{c}}$ thresholds of $6.3 \%$ and $6.5 \%$ (as recommended by the international expert committee) with a fasting plasma glucose threshold of $7.0 \mathrm{mmol} / \mathrm{l}$. The sensitivities of an $\mathrm{HbA}_{1 \mathrm{c}}$ threshold of $6.3 \%$ and this fasting plasma glucose concentration in detecting undiagnosed diabetes were $62.8 \%(57.1 \%$ to $68.3 \%)$ and $57.5 \%(51.7 \%$ to $63.1 \%) \quad(\mathrm{P}=0.183)$. However, the sensitivity of an $\mathrm{HbA}_{1 \mathrm{c}}$ threshold of $6.5 \%$ was $50.5 \% \quad(44.7 \%$ to $56.3 \%)$, which was not significantly different from that of fasting plasma glucose $(\mathrm{P}=0.086)$. At an $\mathrm{HbA}_{1 \mathrm{c}}$ threshold of $6.5 \%$ (table 2 ), the positive and negative predictive values were $63.1 \%(56.6 \%$ to $69.2 \%)$ and $96.8 \%(96.2 \%$ to $97.3 \%)$ and the positive and negative likelihood ratios were 26.0 (20.6 to 32.9$)$ and 0.5 ( 0.5 to 0.6). Interestingly, the sensitivity of an $\mathrm{HbA}_{1 \mathrm{c}}$ threshold of $6.3 \%$ was higher than that of an $\mathrm{HbA}_{1 \mathrm{c}}$ threshold of $6.5 \%(\mathrm{P}=0.002)$.

We did a subgroup analysis of 3639 participants at high risk of diabetes (1436 men and 2203 women). The risk factors for diabetes included age over 45 and body mass index over 24.0. ${ }^{520}$ The median age of this subgroup was 53.4 (interquartile range 47.0-60.3) years. Table 3 shows the sensitivity, specificity, positive and negative predictive value, and positive and negative likelihood ratio for identifying diabetes at different $\mathrm{HbA}_{1 \mathrm{c}}$ thresholds. At an $\mathrm{HbA}_{1 \mathrm{c}}$ threshold of $6.3 \%$, the sensitivity was significantly higher than that of a fasting plasma glucose threshold of $7.0 \mathrm{mmol} / \mathrm{l}$ (66.9\% (61.0\% to $72.5 \%)$ v $54.4 \%(48.3 \%$ to $60.4 \%)$; $\mathrm{P}=0.003)$ with high specificity $(94.8 \%, 94.0 \%$ to $95.6 \%)$. When we used a threshold of $6.5 \%$, the sensitivity was significantly lower than that seen with a $6.3 \%$ threshold (53.7\% (47.6\% to $59.7 \%) v 66.9 \%(61.0 \%$ to 72.5\%); $\mathrm{P}=0.002)$.

Of the 367 participants with $\mathrm{HbA}_{1 \mathrm{c}}$ of $6.3 \%$ or above (table 4), 74 had normal glucose tolerance, 104 had impaired glucose regulation, and 189 were designated as having diabetes when we applied the 1999 WHO criteria. In contrast, at the $\mathrm{HbA}_{1 \mathrm{c}}$ threshold of $6.5 \%$, 33 had normal glucose tolerance, 56 had impaired glucose regulation, and 152 were designated as having diabetes.

Table 5 shows the number and clinical characteristics of patients identified as having diabetes on the basis of oral glucose tolerance test results with the 1999 WHO criteria and an $\mathrm{HbA}_{1 \mathrm{c}}$ threshold of $6.3 \%$. One hundred and eighty-nine of the patients identified by $\mathrm{HbA}_{1 \mathrm{c}}$ overlapped with those diagnosed by using the WHO criteria. The anthropometric and biochemical measurements were comparable between the two groups.

\section{DISCUSSION}

In this community based study in 4886 Chinese adults, we found that an $\mathrm{HbA}_{1 \mathrm{c}}$ threshold of $6.3 \%$ had high specificity for detecting undiagnosed diabetes and equal sensitivity to that of a fasting plasma glucose threshold of $7.0 \mathrm{mmol} / \mathrm{l}$. This threshold was more efficient in the people at high risk of diabetes.

\section{Epidemiology of diabetes}

Although the prevalence of diabetes mellitus has dramatically increased in recent years in China, the disease remains underdiagnosed. In the United States, for every two patients diagnosed as having diabetes in a hospital, at least one other patient in the hospital may have unrecognised diabetes and be at higher risk of poor health outcomes and high healthcare costs. ${ }^{2}$ The epidemiological survey for diabetes in Shanghai, China, found that the annual incidence of diabetes was

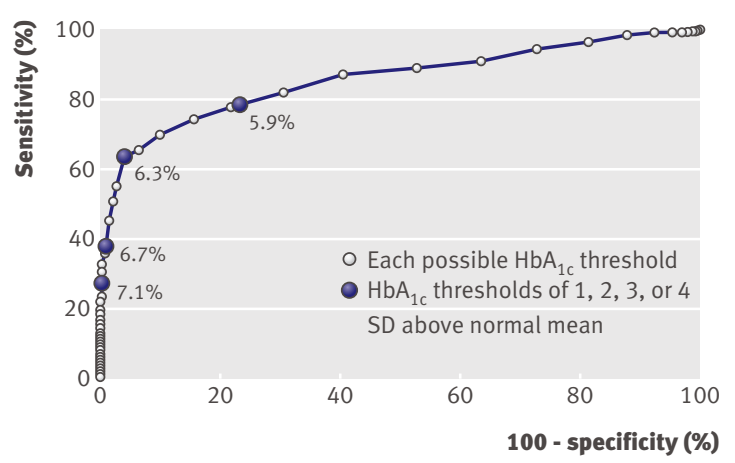

Fig 2 Receiver operating characteristics curve of $\mathrm{HbA}_{1 \mathrm{c}}$ for detecting diabetes at each possible $\mathrm{HbA}_{1 \mathrm{c}}$ threshold. Area under curve $=0.856(95 \% \mathrm{Cl} 0.828$ to 0.883$)$ 
Table $3 \mid$ Sensitivity, specificity, positive predictive value, negative predictive value, positive likelihood ratio, and negative likelihood ratio for detecting diabetes with fasting plasma glucose (FPG) in 1999 WHO criteria and $\mathrm{HbA}_{1 \mathrm{c}}$ thresholds in patients at high risk of developing diabetes ( $\mathrm{n}=3639$ ). Values in parentheses are $95 \%$ confidence intervals

Sensitivity

(\%)
Specificity

(\%)
Positive predictive value

(\%)
Negative predictive value (\%)
Positive likelihood ratio
Negative likelihood ratio

$\mathrm{HbA}_{1 \mathrm{c}}$ threshold (\%):

\begin{tabular}{|c|c|c|c|c|c|c|}
\hline 6.0 & 79.0 (73.7 to 83.7) & 80.3 (78.9 to 81.6$)$ & $24.5(21.7$ to 27.5$)$ & 97.9 (97.3 to 98.4$)$ & $4.0(3.7$ to 4.4$)$ & $0.3(0.2$ to 0.3$)$ \\
\hline 6.1 & 73.9 (68.3 to 79.0$)$ & 87.2 (86.0 to 88.3$)$ & 31.8 (28.1 to 35.5$)$ & 97.6 (97.0 to 98.2$)$ & 5.8 (5.1 to 6.5$)$ & $0.3(0.3$ to 0.4$)$ \\
\hline 6.2 & 69.1 (63.3 to 74.6$)$ & 91.9 (90.9 to 92.8$)$ & 40.7 (36.2 to 45.3$)$ & 97.4 (96.7 to 97.9$)$ & 8.5 (7.4 to 9.8$)$ & $0.3(0.3$ to 0.4$)$ \\
\hline 6.3 & $66.9(61.0$ to 72.5$)$ & 94.8 (94.0 to 95.6$)$ & 51.1 (45.8 to 56.4$)$ & 97.3 (96.6 to 97.8$)$ & 13.0 (11.0 to 15.3$)$ & $0.4(0.3$ to 0.4$)$ \\
\hline 6.4 & 58.8 (52.7 to 64.7$)$ & 96.5 (95.8 to 97.1$)$ & $57.6(51.5$ to 63.4$)$ & 96.7 (96.0 to 97.3 ) & 16.8 (13.7 to 20.6$)$ & $0.4(0.4$ to 0.5$)$ \\
\hline $6.5^{*}$ & 53.7 (47.6 to 59.7$)$ & 97.4 (96.8 to 97.9$)$ & 62.7 (56.1 to 68.9$)$ & 96.3 (95.6 to 96.9) & 20.8 (16.4 to 26.3$)$ & $0.5(0.4$ to 0.5$)$ \\
\hline $\mathrm{FPG} \geq 7.0 \mathrm{mmol} / \mathrm{l}$ & $54.4(48.3$ to 60.4$)$ & $100.0(99.9$ to 100.0$)$ & $100.0(97.5$ to 100.0$)$ & 96.5 (95.8 to 97.0$)$ & - & $0.5(0.4$ to 0.5$)$ \\
\hline
\end{tabular}

*Threshold recommended by American Diabetes Association/European Association for the Study of Diabetes/International Diabetes Federation.

$1.65 \%$ and the prevalence was $6.87 \%$; more than $40 \%$ of people with diabetes were undiagnosed before the survey. ${ }^{2}$ More efficient identification of people with diabetes is thus essential to allow provision of timely treatment and improve outcomes.

\section{Advantages of $\mathrm{HbA}_{1 \mathrm{c}}$ in diagnosing diabetes}

Historically, a lack of standardised $\mathrm{HbA}_{1 \mathrm{c}}$ measurements has meant that the American Diabetes Association has not recommended the use of $\mathrm{HbA}_{1 \mathrm{c}}$ as a diagnostic tool. However, recent improvements in standardised $\mathrm{HbA}_{1 \mathrm{c}}$ measurements worldwide, especially a new more specific reference measure developed in 2003, ${ }^{22}$ have prompted re-evaluation of $\mathrm{HbA}_{1 \mathrm{c}}$ as a screening or diagnostic tool for diabetes. ${ }^{1}$ Selvin et al found that the within-person coefficients of variation in two hour post-load plasma glucose, fasting plasma glucose, and $\mathrm{HbA}_{1 \mathrm{c}}$ were in descending frequency $(16.7 \%>5.7 \%>3.6 \%) .{ }^{23}$ These findings showed that $\mathrm{HbA}_{1 \mathrm{c}}$ was more reproducible and repeatable than fasting plasma glucose as a diagnostic tool for diabetes. $^{24}$

A few practical considerations support the convenience of $\mathrm{HbA}_{1 \mathrm{c}}$ in diagnosing diabetes. Firstly, both fasting plasma glucose and oral glucose tolerance tests require the patient to fast for at least eight hours, which decreases the opportunities for diagnosing diabetes. However, $\mathrm{HbA}_{1 \mathrm{c}}$ testing can be done at any time without fasting or other preparation of the patient, which makes diagnosis on the same day possible. Secondly, both fasting plasma glucose and oral glucose tolerance tests may be affected by short term lifestyle changes, such as diet and amount of physical exercise

Table 4 |Distribution of participants with normal glucose tolerance, impaired glucose regulation, and diabetes stratified by $\mathrm{HbA}_{1 \mathrm{c}}$ thresholds of $6.3 \%$ and $6.5 \%$. Values are numbers (percentages)

\begin{tabular}{lccc} 
& \multicolumn{3}{c}{75 g oral glucose tolerance test } \\
\cline { 2 - 4 } $\mathrm{HbA}_{1 \mathrm{c}}(\%)$ & $\begin{array}{c}\text { Normal glucose tolerance } \\
(\mathrm{n}=3748)\end{array}$ & $\begin{array}{c}\text { Impaired glucose regulation } \\
(\mathrm{n}=837)\end{array}$ & $\begin{array}{c}\text { Diabetes } \\
(\mathrm{n}=301)\end{array}$ \\
$\geq 6.3^{*}$ & $74(2.0)$ & $104(12.4)$ & $189(62.8)$ \\
\hline$\geq 6.5 \dagger$ & $33(0.9)$ & $56(6.7)$ & $152(50.5)$ \\
\hline
\end{tabular}

*Threshold found in this study.

†Threshold recommended by American Diabetes Association/European Association for the Study of Diabetes/ International Diabetes Federation. before examination. In contrast, the $\mathrm{HbA}_{1 \mathrm{c}}$ value does not have such limitations as it reflects mean glycaemia over the preceding two to three months, which accurately reflects longer term glycaemia.

Recent studies have indicated that $\mathrm{HbA}_{1 \mathrm{c}}$ is similar or superior to fasting plasma glucose in screening for or diagnosis of diabetes compared with the gold standard, the oral glucose tolerance test. ${ }^{13}{ }^{15}$ In our study, the area under the receiver operating characteristics curve was 0.856 for $\mathrm{HbA}_{1 \mathrm{c}}$ for detecting undiagnosed diabetes, which corresponds to the findings of a study done in the Japanese population. ${ }^{12}$ Another study found that $\mathrm{HbA}_{1 \mathrm{c}}$ measurement improved the detection of diabetes in people at high risk compared with a fasting plasma glucose threshold of $7.0 \mathrm{mmol} / \mathrm{l}^{25}$

\section{Ethnic differences in distribution of hyperglycaemic categories}

Ethnic differences exist in the distribution of hyperglycaemic categories. The Diabetes Epidemiology: Collaborative Analysis of Diagnostic Criteria in Europe study showed that the proportions of patients with isolated high fasting plasma glucose concentrations, isolated high two hour post-load plasma glucose concentrations, and high fasting plasma glucose concentrations with high two hour post-load plasma glucose concentrations were $40 \%, 31 \%$, and $29 \% .{ }^{26}$ Using only fasting plasma glucose concentrations, about two thirds of patients with diabetes could be detected. ${ }^{27}$ However, the Diabetes Epidemiology: Collaborative Analysis of Diagnostic Criteria in Asia study found corresponding proportions of $19 \%, 44 \%$, and $37 \%$. Therefore, only $56 \%$ of patients with diabetes could be detected with the fasting plasma glucose criterion alone, which left more Asian patients undiagnosed than was the case in the European population. ${ }^{28}$ The 1994 China National Diabetes Mellitus Survey of Chinese adults showed that impaired glucose tolerance was the most common form of impaired glucose regulation and that high fasting plasma glucose concentrations with high two hour post-load plasma glucose concentrations was the most common subcategory of diabetes. ${ }^{29}$ Our study confirmed the findings of the China National Diabetes Mellitus Survey, which suggested that a large number of people with diabetes 
Table $\mathbf{5}$ |Clinical characteristics of participants identified as having diabetes by oral glucose tolerance test and $\mathrm{HbA}_{1 \mathrm{c}}$ threshold of $6.3 \%$. Values are medians (interquartile ranges) unless stated otherwise

\begin{tabular}{|c|c|c|}
\hline Characteristics & $\begin{array}{l}\text { Diabetes identified by oral glucose tolerance test } \\
\qquad(n=301)\end{array}$ & $\begin{array}{l}\text { Diabetes identified by } \mathrm{HbA}_{1 \mathrm{c}} \\
\qquad(\mathrm{n}=367)\end{array}$ \\
\hline Mean (SD) age (years) & $54.2(11.9)$ & $56.4(10.4)$ \\
\hline Mean (SD) body mass index $\left(\mathrm{kg} / \mathrm{m}^{2}\right)$ & $25.5(3.7)$ & $25.8(3.5)$ \\
\hline Mean (SD) waist circumference $(\mathrm{cm})$ & $86.4(10.6)$ & $86.9(9.8)$ \\
\hline Systolic blood pressure $(\mathrm{mm} \mathrm{Hg})$ & $130.0(120.0-140.0)$ & $130.0(120.0-140.0)$ \\
\hline Diastolic blood pressure $(\mathrm{mm} \mathrm{Hg})$ & $80.0(74.0-90.0)$ & $80.0(74.0-90.0)$ \\
\hline Total cholesterol (mmol/l) & $5.0(4.4-5.7)$ & $5.2(4.4-5.8)$ \\
\hline Triglycerides (mmol/l) & $1.8(1.2-2.9)$ & $1.9(1.3-2.9)$ \\
\hline High density lipoprotein cholesterol (mmol/l) & Mean $1.2(\mathrm{SD} 0.3)$ & $1.2(1.0-1.4)$ \\
\hline Low density lipoprotein cholesterol (mmol/l) & $3.1(2.7-3.7)$ & Mean 3.3 (SD 1.0) \\
\hline Fasting plasma glucose (mmol/l) & $7.2(6.2-8.1)$ & $6.4(5.7-7.4)$ \\
\hline 2 hour post-load plasma glucose (mmol/l) & $12.7(11.2-15.2)$ & $10.3(7.2-13.9)$ \\
\hline $\mathrm{HbA}_{1 \mathrm{c}}(\%)$ & $6.5(5.9-7.1)$ & $6.6(6.4-7.0)$ \\
\hline
\end{tabular}

$(>40 \%)$ would be undiagnosed if only the fasting plasma glucose test was used. Accordingly, in the Chinese population, use of $\mathrm{HbA}_{1 \mathrm{c}}$ would be more suitable for diagnosing diabetes according to the distribution of types of hyperglycaemia.

\section{$\mathrm{HbA}_{1 \mathrm{c}}$ threshold compared with other studies}

Racial disparities in $\mathrm{HbA}_{1 \mathrm{c}}$ values exist, ${ }^{3031}$ and the optimal thresholds for detecting diabetes have been found to vary by ethnic group. ${ }^{1215}$ The 1999-2004 National Health and Nutrition Examination Survey found that an $\mathrm{HbA}_{1 \mathrm{c}}$ value of $6.5 \%$ or greater was an optimal threshold for identifying diabetes in the US population. ${ }^{10}$ Data from the National Health and Nutrition Examination Survey III (1988-94) found indications of differences between ethnic groups in the sensitivity and specificity of $\mathrm{HbA}_{1 \mathrm{c}}$ (at $6.1 \%$ ) for detecting undiagnosed diabetes. Sensitivity ranged from $58.6 \%$ in the non-Hispanic white population to $83.6 \%$ in the Mexican-American population; specificity ranged from $93.0 \%$ in the non-Hispanic black population to $98.3 \%$ in the non-Hispanic white population. ${ }^{11}$ In a multiethnic population in Canada, the optimal threshold for $\mathrm{HbA}_{1 \mathrm{c}}$ of $5.9 \%$ was associated with a sensitivity of $75.0 \% \quad(95 \%$ confidence interval $64.0 \%$ to $86.0 \%$ ) and a specificity of $79.1 \%$ $(76.4 \%$ to $81.8 \%) .{ }^{32}$ A study of the Hong Kong Chinese population with known risk factors for glucose intolerance showed that an $\mathrm{HbA}_{1 \mathrm{c}}$ threshold of $6.1 \%$ gave an optimal sensitivity of $77.5 \%$ and specificity of $78.8 \%$ when two hour post-load plasma glucose of at least $11.1 \mathrm{mmol} / 1$ was used as the reference. ${ }^{33}$ Similar results were found in the Japanese population, where the $\mathrm{HbA}_{1 \mathrm{c}}$ threshold of $6.1 \%$ was found to be suitable for detecting undiagnosed diabetes and predicting vascular complications. ${ }^{12}$

In our community based study, we found that an $\mathrm{HbA}_{1 \mathrm{c}}$ threshold of $5.9 \%$ provided the optimal sensitivity and specificity for screening for potential diabetes in the general Chinese population. Recently, an international expert committee reported that people with an $\mathrm{HbA}_{1 \mathrm{c}}$ value of at least $6 \%$ but less than $6.5 \%$ are likely to be at highest risk for progression to diabetes. ${ }^{16}$ In our study, the proficiency of an $\mathrm{HbA}_{1 \mathrm{c}}$ threshold of $6.3 \%$ for detecting diabetes was equivalent to that of a fasting plasma glucose threshold of $7.0 \mathrm{mmol} / \mathrm{l}$. However, in people at high risk of diabetes, the proficiency of an $\mathrm{HbA}_{1 \mathrm{c}}$ threshold of $6.3 \%$ in detecting diabetes was superior to that of both a fasting plasma glucose threshold of $7.0 \mathrm{mmol} / \mathrm{l}$ and an $\mathrm{HbA}_{1 \mathrm{c}}$ threshold of $6.5 \%(66.9 \%$ v $54.4 \%$ v $53.7 \%)$. On the basis of our results, an $\mathrm{HbA}_{1 \mathrm{c}}$ threshold of $6.3 \%$ may be acceptable as a diagnostic criterion for diabetes in the Chinese population, when fasting plasma glucose and oral glucose tolerance tests are not available.

\section{Confounders and limitations of study}

Some confounders and effect modifiers influence the clinical use of $\mathrm{HbA}_{1 \mathrm{c}}$ for screening for and diagnosis of diabetes. Firstly, the $\mathrm{HbA}_{1 \mathrm{c}}$ value reflects mean glycaemia over the preceding two to three months, so people with a history of diabetes of less than three months might not be identified by $\mathrm{HbA}_{1 \mathrm{c}}$ testing. However, this is extremely unlikely given that on average a seven year gap exists between the actual onset of diabetes and its diagnosis. ${ }^{34}$ Secondly, conditions that shorten survival of erythrocytes, such as haemolytic anaemia, will decrease the concentration of $\mathrm{HbA}_{1 \mathrm{c}}$ Conversely, conditions that prolong the age of erythrocytes, such as splenectomy and aplastic anaemia, will increase the concentration of $\mathrm{HbA}_{1 \mathrm{c}}$ independent of glycaemia. Haemoglobinopathies such as haemoglobin $\mathrm{S}$ (sickle cell) interfere with some assays. Thus, the use of $\mathrm{HbA}_{1 \mathrm{c}}$ may be inappropriate for such disorders.

Limitations of this study include an inadequate sample size. Additionally, as the high prevalence of impaired glucose tolerance has prognostic value regarding possible progression to diabetes and cardiovascular disease, the use of $\mathrm{HbA}_{1 \mathrm{c}}$ alone to diagnose diabetes could give a false sense of security. Thus, in patients with known risk factors for glucose intolerance, a $75 \mathrm{~g}$ oral glucose tolerance test, yearly $\mathrm{HbA}_{1 \mathrm{c}}$ 


\section{WHAT IS ALREADY KNOWN ON THIS TOPIC}

$\mathrm{HbA}_{1 \mathrm{c}}$ might be a useful tool for screening for and diagnosis of diabetes

In June 2009, an international expert committee published a report recommending the use of an $\mathrm{HbA}_{1 \mathrm{c}}$ value of $6.5 \%$ or more as a diagnostic criterion for diabetes

As racial disparities in $\mathrm{HbA}_{1 \mathrm{c}}$ levels exist, the optimal threshold for diagnosing diabetes varies by ethnic group

\section{WHAT THIS STUDY ADDS}

In the Chinese population, an $\mathrm{HbA}_{1 \mathrm{c}}$ threshold of $6.3 \%$ may be acceptable as a diagnostic criterion for diabetes

In people at high risk of diabetes, an $\mathrm{HbA}_{1 \mathrm{c}}$ threshold of $6.3 \%$ was more efficient than a fasting plasma glucose threshold of $7.0 \mathrm{mmol} / \mathrm{l}$
Data sharing: No additional data available.

1 Saudek CD, Herman WH, Sacks DB, Bergenstal RM, Edelman D, Davidson MB. A new look at screening and diagnosing diabetes mellitus. J Clin Endocrinol Metab 2008;93:2447-53.

2 Jia WP, Pang C, Chen L, Bao YQ, Lu JX, Lu HJ, et al. Epidemiological characteristics of diabetes mellitus and impaired glucose regulation in a Chinese adult population: the Shanghai Diabetes Studies, a cross-sectional 3-year follow-up study in Shanghai urban communities. Diabetologia 2007;50:286-92.

3 World Health Organization. The world health report: primary health care-now more than ever. WHO, 2008.

4 World Health Organization. Definition, diagnosis and classification of diabetes mellitus and its complications: report of a WHO consultation. Part 1: diagnosis and classification of diabetes mellitus. WHO, 1999.

5 Expert Committee on the Diagnosis and Classification of Diabetes Mellitus. Report of the expert committee on the diagnosis and classification of diabetes mellitus. Diabetes Care 2003;26(suppl 1):S5-20.

6 Little RR, Rohlfing CL, Wiedmeyer HM, Myers GL, Sacks DB, Goldstein DE, et al. The national glycohemoglobin standardization program: a five-year progress report. Clin Chem 2001;47:1985-92.

measurement, or both are needed to avoid missed diagnosis and opportunity for therapeutic intervention. Although either plasma glucose concentrations after fasting or two hour post-load plasma glucose after a $75 \mathrm{~g}$ oral glucose tolerance test could be used alone for diagnosing diabetes in epidemiological studies, according to 1999 WHO criteria, ${ }^{4}$ additional testing is desirable to prove the reliability of the $\mathrm{HbA}_{1 \mathrm{c}}$ threshold in clinical studies. This study should be validated by similar epidemiological and clinical studies.

\section{Financial implications}

The cost in China of the $\mathrm{HbA}_{1 \mathrm{c}}$ test was similar to that of the oral glucose tolerance test. However, the first of these is more acceptable to patients than the second, because it causes less discomfort. Undiagnosed diabetes and its complications cause increased healthcare costs in America. ${ }^{35}$ On the basis of our study, $\mathrm{HbA}_{1 \mathrm{c}}$ testing might help to reduce these costs by improving diagnosis of diabetes and enabling more timely therapeutic intervention in such patients.

\section{Conclusions}

In conclusion, this study found that an $\mathrm{HbA}_{1 \mathrm{c}}$ threshold of $6.3 \%$ was highly specific for detecting undiagnosed diabetes in Chinese adults and had sensitivity similar to that of using a fasting plasma glucose threshold of $7.0 \mathrm{mmol} / \mathrm{l}$. These findings suggest that $\mathrm{HbA}_{1 \mathrm{c}}$, with the optimal threshold of $6.3 \%$, may be acceptable as a diagnostic criterion for diabetes in the Chinese population when fasting plasma glucose and oral glucose tolerance tests are not available.

Contributors: $\mathrm{YB}, \mathrm{XK}$, and $\mathrm{WJ}$ conceived and designed the study. $\mathrm{XM}$ and $\mathrm{XH}$ recruited samples. $\mathrm{XM}$ did the statistical analyses. JT measured $\mathrm{HbA}_{1}$ $Y B$ and $X M$ wrote the first draft of the paper. $Y B, X M, C H$, and WJ revised the paper and contributed to discussion. $\mathrm{HL}, \mathrm{MZ}$, and $\mathrm{HW}$ provided technical support. YB and XM contributed equally to this work and are the guarantors

Funding: This work was funded by Shanghai United Developing Technology Project of Municipal Hospitals (SHDC12006101), Chinese National 973 Project (2007CB914702), Shanghai Key Laboratory of Diabetes Mellitus (08DZ2230200), Major Program of Shangha Municipality for Basic Research (08dj1400601), and National Key Technology R\&D Program of China (2009BAI80B01).

Competing interests: None declared.

Ethical approval: The local ethics committee approved the study, and all participants gave written informed consent. 
27 DECODE Study Group. Glucose tolerance and cardiovascular mortality: comparison of fasting and 2-hour diagnostic criteria. Arch Intern Med 2001;161:397-405.

28 Qiao Q, Nakagami T, Tuomilehto J, Borch-Johnsen K, Balkau B, Iwamoto $\mathrm{Y}$, et al. Comparison of the fasting and the 2-h glucose criteria for diabetes in different Asian cohorts. Diabetologia 2000;43:1470-5.

29 Yang ZJ, Yang WY, Li GW; National Diabetes Prevention and Control Cooperative Group. The distributive characteristics of impaired glucose metabolism subcategories in Chinese adult population. Zhonghua Yi Xue Za Zhi 2003;83:2128-31.

30 Herman WH, Ma Y, Uwaifo G, Haffner S, Kahn SE, Horton ES, et al. Differences in $\mathrm{A} 1 \mathrm{C}$ by race and ethnicity among patients with impaired glucose tolerance in the Diabetes Prevention Program. Diabetes Care 2007;30:2753-7.

31 Viberti G, Lachin J, Holman R, Zinman B, Haffner S, Kravitz B, et al. A Diabetes Outcome Progression Trial (ADOPT): baseline characteristics of type 2 diabetic patients in North America and Europe. Diabet Med 2006;23:1289-94.

32 Anand SS, Razak F, Vuksan V, Gerstein HC, Malmberg K, Yi Q, et al. Diagnostic strategies to detect glucose intolerance in a multiethnic population. Diabetes Care 2003;26:290-6.

33 Ko GT, Chan JC, Yeung VT, Chow CC, Tsang LW, Li JK, et al. Combined use of a fasting plasma glucose concentration and $\mathrm{HbA}_{1 \mathrm{c}}$ or fructosamine predicts the likelihood of having diabetes in high-risk subjects. Diabetes Care 1998;21:1221-5.

34 Harris MI. Undiagnosed NIDDM: clinical and public health issues. Diabetes Care 1993;16:642-52.

35 Zhang Y, Dall TM, Mann SE, Chen Y, Martin J, Moore V, et al. The economic costs of undiagnosed diabetes. Popul Health Manag 2009;12:95-101.

Accepted: 6 April 2010 